\title{
Risk factors for excess weight loss and hypernatremia in exclusively breast-fed infants
}

M.K. Çağlar, I. Özer and F.Ş. Altugan
Department of Pediatrics, Faculty of Medicine, Gaziosmanpaşa University, Tokat, Turkey

\section{Correspondence}

M.K. Çağlar

Gaziosmanpaşa Üniversitesi

Tip Fakültesi Hastanesi

Çocuk Sağliği ve Hastaliklari

Anabilim Dali

Tokat

Turkey

Fax: +90-356-212-8031

E-mail: mkc@ttnet.net.tr

Received March 10, 2005

Accepted December 16, 2005

\begin{abstract}
Data were prospectively obtained from exclusively breast-fed healthy term neonates at birth and from healthy mothers with no obstetric complication to determine risk factors for excess weight loss and hypernatremia in exclusively breast-fed infants. Thirty-four neonates with a weight loss $\geq 10 \%$ were diagnosed between April 2001 and January 2005. Six of 18 infants who were eligible for the study had hypernatremia. Breast conditions associated with breast-feeding difficulties ( $\mathrm{P}<0.05)$, primiparity $(\mathrm{P}<0.005)$, less than four stools $(\mathrm{P}<$ $0.001)$, pink diaper $(\mathrm{P}<0.001)$, delay at initiation of first breast giving $(\mathrm{P}<0.01)$, birth by cesarean section $(\mathrm{P}<0.05)$, extra heater usage $(\mathrm{P}$ $<0.005)$, extra heater usage among mothers who had appropriate conditions associated with breast-feeding $(\mathrm{P}<0.001)$, mean weight loss in neonates with pink diaper $(\mathrm{P}<0.05)$, mean uric acid concentration in neonates with pink diaper $(\mathrm{P}<0.0001)$, fever in hypernatremic neonates $(\mathrm{P}<0.02)$, and the correlation of weight loss with both serum sodium and uric acid concentrations $(\mathrm{P}<0.02)$ were determined. Excessive weight loss occurs in exclusively breast-fed infants and can be complicated by hypernatremia and other morbidities. Prompt initiation of breast-feeding after delivery and prompt intervention if problems occur with breast-feeding, in particular poor breast attachment, breast engorgement, delayed breast milk "coming in", and nipple problems will help promote successful breast-feeding. Careful follow-up of breast-feeding dyads after discharge from hospital, especially regarding infant weight, is important to help detect inadequate breast-feeding. Environmental factors such as heaters may exacerbate infant dehydration.
\end{abstract}

\section{Introduction}

Weight loss in the first few days of life of newborn babies is a well-known clinical entity. Mean weight loss is approximately $6 \%$ of birth weight in well babies during the first 3 days (1-3). In a recent report (4), the median and 95th percentiles for weight loss
Key words

- Neonate

- Dehydration

- Breast-feeding

- Hypernatremia

- Weight loss 
in catastrophic outcomes for exclusively breast-fed infants. Both anecdotal reports (5-9) and recent retrospective (10-13) and prospective $(14,15)$ studies indicate an increase in frequency and severity of outcomes of this imbalance.

Data in all these studies have been derived from the records of community-based newborn follow-ups $(4,15)$ and hospital admissions (5,7-14). In the current study, we determined the risk factors for excess weight loss and hypernatremia in exclusively breastfed infants who attended our clinic.

\section{Subjects and Methods}

Infants who were brought by their parents for their first medical intervention after delivery between April 2001 and January 2005 were identified prospectively at the Efe Alp Medical Service and Pediatric Ambulatory Service of the Gaziosmanpaşa Medical Faculty. Enrollment criteria included: entirely healthy (except dehydration) neonates ( 1 case to 4 control neonates) of Turkish parents with a gestational age of more than 36 weeks and weighing more than 2500 $\mathrm{g}$ at birth, and with normal neonatal adaptation; and also healthy mothers who had no obstetric complication before or after delivery and who gave birth to a single baby via scheduled caesarean section or uncomplicated vaginal delivery. Infants with congenital malformations and sucking problems and who had received special medical treatment were excluded. All infants studied were roomed in. Information was obtained about the mother (age, parity, educational level, changes in breast size during pregnancy and after delivery, pathologic engorgement of the breasts, time elapsed between delivery and first breast giving, frequency of breastfeeding in the last 2 days, any pathologic condition, hospital stay) and the neonate (age, birth weight, route of delivery, pink diaper color and mean number of stools over the last 2 days), and the use of an extra heater at home was also recorded.

Thirty-four newborn infants with a weight loss $\geq 10 \%$ were diagnosed between April 2001 and January 2005. Of these, 18 whose ages were between 4 and 9 days (mean: 6.2 days) were eligible for the study. Those with infections (two), cleft palate (one), gestational age $<37$ weeks (four), birth weight $<2500 \mathrm{~g}$ (five), and maternal complication (four) were excluded from the study. Seventy-two neonates with no weight loss or a loss of less than $10 \%$ whose ages were between 5 and 9 days (mean: 6.6 days) and who met the criteria were recruited for the study as a control group.

Each newborn infant included in the study was fully examined by one of the authors. Infants were weighed naked using a digital scale, with an error of $10 \mathrm{~g}$. Status of hydration (turgor, fontanel, mucous membranes) was carefully evaluated. The rectal route was used for body temperature measurement (fever $>37.8^{\circ} \mathrm{C}$ ). Findings of maternal breast examinations were also recorded.

Laboratory investigations (complete blood count, differential counts of white blood cells in a peripheral smear, serum total and direct bilirubin, blood urea nitrogen, creatinine, uric acid, sodium, potassium, chloride, C-reactive protein, interleukin-6, urine analysis) were carried out in all babies who suffered from dehydration.

'Day of age' in the study was defined as the baby's age in hours. Every completed 24-h period thereafter was considered ' 1 day'. A sodium concentration over 149 $\mathrm{mmol} / \mathrm{L}$ was accepted as hypernatremia. Each patient included in the study who had a weight loss $\geq 10 \%$ was matched with four entirely healthy babies who had no weight loss or a weight loss $<10 \%$ selected according to the same criteria.

The Student $t$-test, chi-square test, and Pearson correlation were used for statistical analysis of the data. Values $<0.05$ were considered significant. 


\section{Results}

The characteristics of maternal and neonatal groups with $\geq 10 \%$ weight loss and $<10 \%$ weight loss are summarized in Table 1.

Thirteen mothers of the infants in the study group had concerns about poor weight gain. All babies were alert and active and had a good sucking reflex. None had diarrhea.

Of the 18 infants with a weight loss of more than $10 \%, 6(33.3 \%)$ had hypernatremia ranging from 151 to $168 \mathrm{mmol} / \mathrm{L}$, and 9 (50\%) had fever ranging from $37.9^{\circ}$ to $38.9^{\circ} \mathrm{C}$. Weight loss ranged from 10.17 to $15.76 \%$. None of them needed phototherapy.

The infants with a weight loss of more than $10 \%$ were more likely to be from primiparous mothers $(\mathrm{P}<0.005)$, to have received their first breast-feeding later than the controls $(3.89 \pm 2.37$ vs $2.14 \pm 1.31 \mathrm{~h}, \mathrm{P}<0.01)$, to pass less than 4 stools per day $(\mathrm{P}<0.001)$ and to have pink diaper $(\mathrm{P}<0.001)$. Among babies born by cesarean section, dehydrated babies had a greater delay to first feeding than those who were not $(5.0 \pm 2.35$ vs $1.9 \pm$ $0.7 \mathrm{~h}, \mathrm{P}<0.05)$. There was no significant difference in the age at first feeding among infants delivered vaginally. An extra heater was used more frequently in the dehydrated group $(\mathrm{P}<0.005)$. In addition, in the group of dehydrated infants whose mothers had no breast problems the use of a heater was more common than among the controls $(\mathrm{P}<0.001)$.

Among dehydrated infants, a pink diaper was associated with greater weight loss $(\mathrm{P}<$ $0.05)$ and with a higher uric acid concentration. Weight loss correlated well with serum sodium (r: $0.548, \mathrm{P}<0.02$ ) and uric acid (r: $0.572, \mathrm{P}<0.02)$ concentrations. Bilirubin levels were all below the phototherapy range (mean: $170 \mu \mathrm{mol} / \mathrm{L}$; range: $98-260 \mu \mathrm{mol} / \mathrm{L}$ ).

There was no significant difference between cases and controls in maternal and infant age, maternal educational level, birth weight, route of delivery, mean frequency of breast-feeding, and hospital stay. There was no correlation between weight loss and age at examination, birth weight or maternal age. All babies were managed at home by their mothers.

Breast conditions likely to be associated with breast-feeding problems were identified in the control group. Nine mothers with breast engorgement and four with flat or inverted nipples had managed to successfully breast-feed. Eight mothers of the cases had breast conditions that contributed to breast-feeding difficulties: mammogenesis (breasts which are small and never showed any size change during pregnancy) in one, huge breast engorgement in three, giant nipples in one, and inverted or flat nipples in three.

\begin{tabular}{|c|c|c|c|}
\hline & $\begin{array}{l}\text { Weight loss } \\
\quad \geq 10 \%\end{array}$ & $\begin{array}{l}\text { Weight loss } \\
<10 \%\end{array}$ & $\mathrm{P}$ \\
\hline Number of neonates & 18 & 72 & \\
\hline Primiparity & $15(83.3 \%)$ & $37(51.4 \%)$ & $<0.005$ \\
\hline Pink diaper color & $10(55.6 \%)$ & $7(9.7 \%)$ & $<0.001$ \\
\hline Number of stools $<4$ & $11(61.2 \%)$ & $10(13.9 \%)$ & $<0.001$ \\
\hline Hypernatremia & $6(33.3 \%)$ & & \\
\hline Fever & $9(50.0 \%)$ & & \\
\hline Sodium $\leq 149 \mathrm{mmol} / \mathrm{L}(\mathrm{N}=12)$ & $4(33.3 \%)$ & & $<0.02$ \\
\hline Sodium $>149 \mathrm{mmol} / \mathrm{L}(\mathrm{N}=6)$ & $5(83.3 \%)$ & & \\
\hline $\begin{array}{l}\text { Breast conditions associated with } \\
\text { breast-feeding difficulties (\%) }\end{array}$ & $8(44.4 \%)$ & $13(18.1 \%)$ & $<0.05$ \\
\hline Mean time to first breast-feeding $(\mathrm{h})$ & $3.89 \pm 2.37$ & $2.14 \pm 1.31$ & $<0.01$ \\
\hline \multicolumn{4}{|l|}{ Mean first breast-giving time $(\mathrm{h})$} \\
\hline Neonates delivered by cesarian section & $5.0 \pm 2.35$ & $1.9 \pm 0.7$ & $<0.05$ \\
\hline Neonates born by vaginal delivery & $3.46 \pm 2.33$ & $2.18 \pm 1.4$ & NS \\
\hline Presence of an extra heater (\%) & $12(66.7 \%)$ & $21(29.2 \%)$ & $<0.005$ \\
\hline $\begin{array}{l}\text { Presence of an extra heater under } \\
\text { appropriate conditions associated } \\
\text { with breast-feeding }\end{array}$ & $8(80 \%)$ & $17(28.8 \%)$ & $<0.001$ \\
\hline \multicolumn{4}{|l|}{ Mean weight loss } \\
\hline Pink diapers $(+)$ & $13.97 \pm 1.28(10)$ & & $<0.05$ \\
\hline Pink diapers (-) & $11.67 \pm 1.76(8)$ & & \\
\hline \multicolumn{4}{|l|}{ Mean uric acid levels (mg/dL) } \\
\hline Pink diapers (+) & $7.04 \pm 0.45(10)$ & & $<0.0001$ \\
\hline Pink diapers (-) & $5.76 \pm 0.37(8)$ & & \\
\hline
\end{tabular}

Data are reported as number (\%) or means $\pm \mathrm{SD}$ and the number of neonates is given in parentheses. NS = not significant. 


\section{Discussion}

Breast-feeding is the best and safest way to feed infants. However, inadequate breastfeeding may result in significant weight loss and hypernatremic dehydration (5-15), a potentially lethal condition that can be associated with severe complications $(16,17)$.

The most common cause of excessive weight loss and hypernatremia is inadequate breast milk intake. Lactogenesis stage II, the onset of sufficient milk production, occurs during the first 4 days after delivery (18). It is possible for a suckling infant to get a volume of $<100 \mathrm{~mL} /$ day on the first day of life while milk production rapidly increases to an average of $500 \mathrm{~mL} /$ day by the 4th day (19). Therefore, the recovery of weight loss is expected to occur by the end of the first week. As stated by MacDonald et al. (4), the median time of maximum weight loss and recovery has been determined to be 2.7 and 8.3 days, respectively.

Primary insufficient lactation is a rare condition. As the levels of gestational hormones rise, both structural and functional changes occur in the breasts during gestation, which can be observed by an increase in breast size (18). There was only one mother in the present study whose breasts were small and practically did not change in size (mammogenesis) during pregnancy. She was assigned to the primary insufficient group. Like the other mothers in the study, this mother was highly motivated to feed her baby by her own breast milk, without recognizing dehydration of the baby. The rest of the mothers with flat or inverted or big nipples and huge engorged breasts could not overcome the problem by themselves. Consequently, they failed to feed their babies properly, although their breasts were capable of producing sufficient milk. These mothers and the mother with primary insufficient lactation were assigned to the "breast conditions associated with breast-feeding difficulties" group. The remaining 10 mothers in this group of 18 had no reason to explain inadequate breast-feeding, which probably could be explained by "inefficient maternal milk removal" because of poor breast-feeding technique. Those mothers who seemed to have no breast conditions associated with breast-feeding difficulties to explain dehydration were assigned to the "appropriate breast conditions associated with breast-feeding" group. Secondary reasons for an insufficient milk supply include breast engorgement and inverted, huge or flat nipples. These breast conditions were more likely to be found in the mothers of dehydrated infants. Therefore, antenatally (for the nipple conditions) and postnatally (for the breast engorgement) these mothers could have been identified and additional support for breastfeeding provided. Other maternal breast conditions that have been reported to cause breast-feeding difficulties include previous breast surgery, cracked or painful nipples, systemic maternal illnesses, perinatal complications, and maternal age over 37 years (20).

Previous reports have demonstrated the importance of early initiation of breast-feeding post-delivery for successful lactation (2123). In this study, there was no difference between cases and controls in the frequency of feeding in the 2 days prior to review but there was a significant delay in the age of the neonate at first feeding in the dehydrated group, in particular for babies delivered by cesarean section. Mothers should be helped and supported to breast-feed their infants as soon as possible after delivery. Unnecessary system delays, particularly after cesarean section, should be minimized.

The findings of the current study are consistent with previous reports $(11,15)$ stating that most of the mothers of the neonates with excessive weight loss were primiparas. Therefore, first-time mothers should receive more reassurance and practical advice in the technique of breast-feeding. In the hospital, those who wish to breast-fed should receive 
intensive support and should be trained about how to correctly position the child, appropriately attach it to the breast and observe that suckling is successful.

It has been reported that environmental factors may contribute to dehydration because of increased imperceptible water loss (5). A new finding from the present study was that an extra home heater was more likely to be used in the dehydrated group. Environmental factors in the home could exacerbate dehydration through imperceptible water loss.

Along with other studies, the present one showed that fever $(12,13)$ and hypernatremia $(5,8,10-14)$ are often found in neonates with excessive weight loss. In low-risk fullterm infants, fever with no other symptoms during the first days of life is related primarily to dehydration and breast-feeding, whereas infection is the least common explanation (13). The fever seen in the neonates of the present study was directly related to dehydration because there was no indication of infection and body temperature returned to normal limits in all hyperthermic babies with only the correction of water deprivation. Therefore, fever in neonates with excessive weight loss is called "dehydration fever" (12).

In a 1949 study, sodium (mean \pm SD) was determined to be $22 \pm 12 \mathrm{mmol} / \mathrm{L}$ in colostrum in the first 5 days, $13 \pm 3 \mathrm{mmol} / \mathrm{L}$ in transitional milk from day 5 to 10 , and $7 \pm$ $2 \mathrm{mmol} / \mathrm{L}$ in mature milk after 15 days (24).
It has been well demonstrated that if women fail to establish good breast-feeding, the normal physiological decrease in breast milk sodium concentration does not occur (25). However, sodium returns to normal limits when re-lactation is successfully established (5). Since the poorly fed infant is not able to obtain a high sodium content from a low volume of breast milk, hypernatremia because of water deprivation and a secondary accumulation of sodium in an attempt to maintain circulating volume occurs. A case with esophageal atresia who lost $20 \%$ of her birth weight and had a serum sodium concentration of $158 \mathrm{mmol} / \mathrm{L}$ at 6 days of age supports this interpretation since she was not able to receive any amount of breast milk into her stomach (11).

Excessive weight loss occurs in exclusively breast-fed infants and can be complicated by hypernatremia and other morbidities. Prompt initiation of breast-feeding after delivery and prompt intervention if problems with breast-feeding occur, in particular poor breast attachment, breast engorgement, delayed breast milk "coming in" and nipple problems, will help promote successful breast-feeding. Careful follow-up of breastfeeding dyads after discharge from hospital, particularly regarding infant weight, is an important tool to help detect inadequate breast-feeding. Environmental factors such as extra heaters may exacerbate the infant's dehydration.

\section{References}

1. Maisels MJ \& Gifford K (1983). Breast feeding, weight loss and jaundice. Journal of Pediatrics, 102: 117-118.

2. Maisels MJ, Gifford K, Antle CE et al. (1988). Jaundice in the healthy newborn infant: a new approach to an old problem. Pediatrics, 81: 505-511.

3. Marchini G \& Stock S (1997). Thirst and vasopressin secretion counteract dehydration in newborn infants. Journal of Pediatrics, 130: 736-739.

4. MacDonald PD, Ross SRM, Grant L et al. (2003). Neonatal weight loss in breast and formula fed infants. Archives of Disease in Child- hood. Fetal and Neonatal Edition, 88: F472-F476.

5. Sofer S, Ben-Ezer D \& Dagan R (1993). Early severe dehydration in young breast-fed newborn infants. Israel Journal of Medical Sciences, 29: 85-89.

6. Smith RG (1998). Severe hypernatremic dehydration in a newborn infant. Paediatrics and Child Health, 3: 413-415.

7. Pascale JA, Brittian L, Lenfestey CC et al. (1996). Breast-feeding, dehydration, and shorter maternity stays. Neonatal Network, 15: 3743.

8. Paul AC, Ranjini K, Muthulakshmi RA et al. (2000). Malnutrition and 
hypernatremia in breast-fed babies. Annals of Tropical Paediatrics, 20: 179-183.

9. Harding D, Cairns P, Gupta S et al. (2001). Hypernatremia: why bother weighing breast fed babies? Archives of Disease in Childhood. Fetal and Neonatal Edition, 85: F145.

10. Cooper WO, Atherton HD, Kahana M et al. (1995). Increased incidence of severe breast-feeding malnutrition and hypernatremia in a metropolitan area. Pediatrics, 96: 957-960.

11. Oddie S, Richmond S \& Coulthard M (2001). Hypernatraemic dehydration and breast feeding: a population study. Archives of Disease in Childhood, 85: 318-320.

12. Zachariassen G \& Juvonen P (2002). Neonatal dehydration (dehydration fever) in newborn infants. Ugeskrift for Laeger, 164: 49304934.

13. Maayan-Metzger A, Mazkereth R \& Kuint J (2003). Fever in healthy asymptomatic newborns during the first days of life. Archives of Disease in Childhood. Fetal and Neonatal Edition, 88: F312-F314.

14. Manganaro R, Mamí C, Marrone T et al. (2001). Incidence of dehydration and hypernatremia in exclusively breast-fed infants. Journal of Pediatrics, 139: 673-675.

15. Dewey KG, Nommsen-Rivers LA, Heinig MJ et al. (2003). Risk factors for suboptimal infant breast-feeding behavior, delayed onset of lactation, and excess neonatal weight loss. Pediatrics, 112: 607619.
16. Laing IA \& Wong CM (2002). Hypernatraemia in the first few days: is the incidence rising? Archives of Disease in Childhood. Fetal and Neonatal Edition, 87: F158-F162.

17. Korkmaz A, Yigit S, Firat M et al. (2000). Cranial MRI in neonatal hypernatraemic dehydration. Pediatric Radiology, 30: 323-325.

18. Neville MC \& Morton J (2001). Physiology and endocrine changes underlying human lactogenesis II. Journal of Nutrition, 131: 3005 S3008 S.

19. Neville MC, Allen JC, Archer P et al. (1991). Studies in human lactation: milk volume and nutrient composition during weaning and lactogenesis. American Journal of Clinical Nutrition, 54: 81-93.

20. Neifert MR (2001). Prevention of breast-feeding tragedies. Pediatric Clinics of North America, 48: 273-297.

21. Salariya E, Easton P \& Cater J (1978). Duration of breast-feeding after early initiation and frequent feeding. Lancet, 2: 1141-1143.

22. Chapman DJ \& Pérez-Escamilla R (2000). Maternal perception of the onset of lactation is a valid, public health indicator of lactogenesis stage II. Journal of Nutrition, 130: 2972-2980.

23. Sozmen M (1992). Effects of early suckling of caesarean-born babies on lactation. Biology of the Neonate, 62: 67-68.

24. Macy IG (1949). Composition of human colostrum and milk. American Journal of Diseases of Children, 78: 589-603.

25. Morton JA (1994). The clinical usefulness of breast milk sodium in the assessment of lactogenesis. Pediatrics, 93: 802-806. 